\title{
A much cleaner oxidation process for 2,2'- dibenzothiazole disulfide synthesis catalyzed by phosphotungstic acid
}

\author{
Jiaxin Tian, Zifei Yan, Jian Deng, Guangsheng Luo* \\ The State Key Laboratory of Chemical Engineering, Department of Chemical \\ Engineering, Tsinghua University, Beijing 100084, China
}

The State Key Laboratory of Chemical Engineering, Department of Chemical Engineering, Tsinghua University, Beijing 100084, China.

E-mail: gsluo@tsinghua.edu.cn; Fax: +86 0106278 3870; Tel: +86 01062783870 


\section{Supporting information}

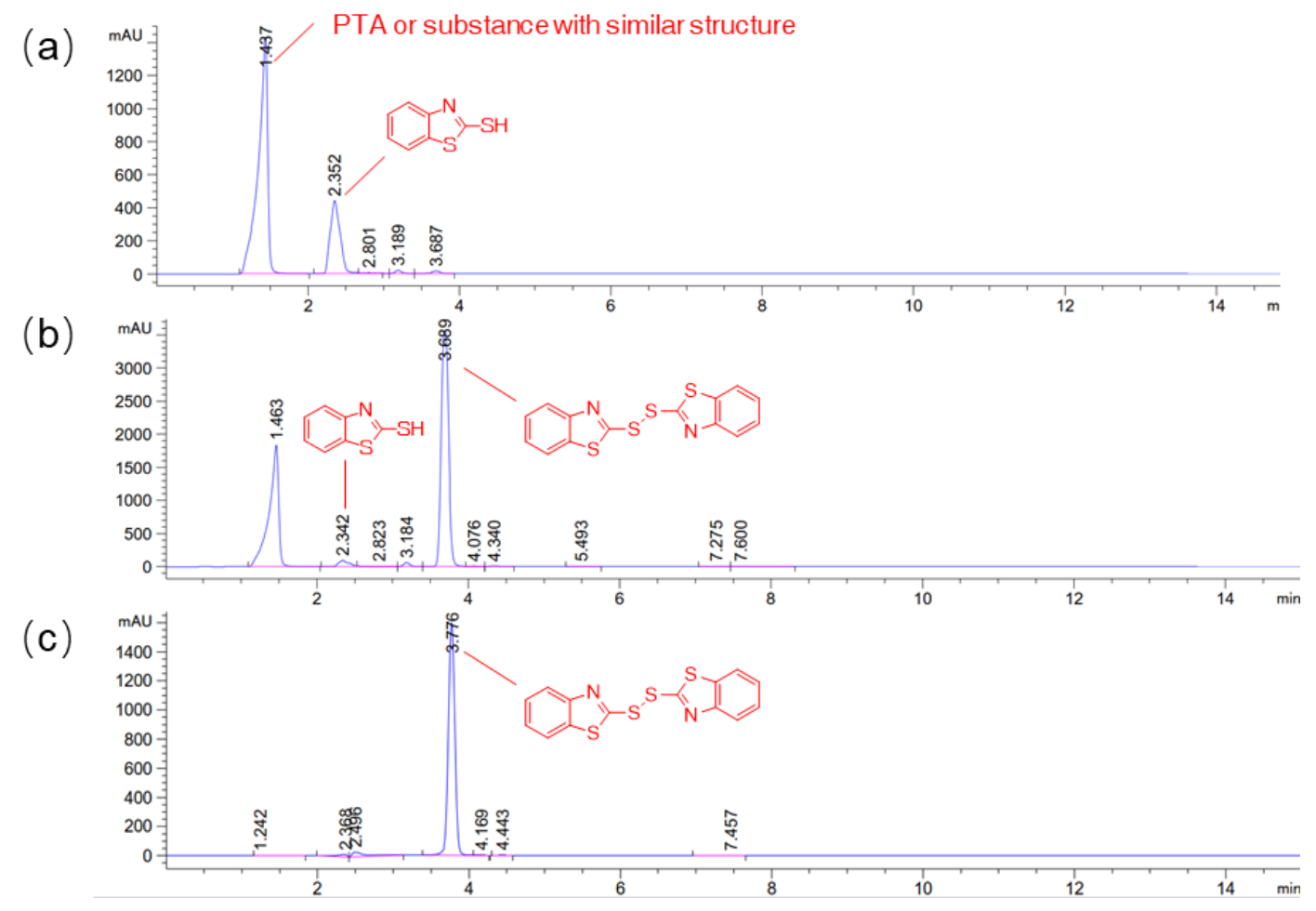

Figure S1. HPLC chromatograms (a) MBT in tert-butanol solution with PTA. (b) the solid-liquid mixture completely dissolved in DMSO after reaction. (c) the standard MBTS ( $\geq 99.0 \mathrm{wt} \%) .(0.5 \mathrm{~mL} / \mathrm{min}$ acetonitrile as the mobile phase) 

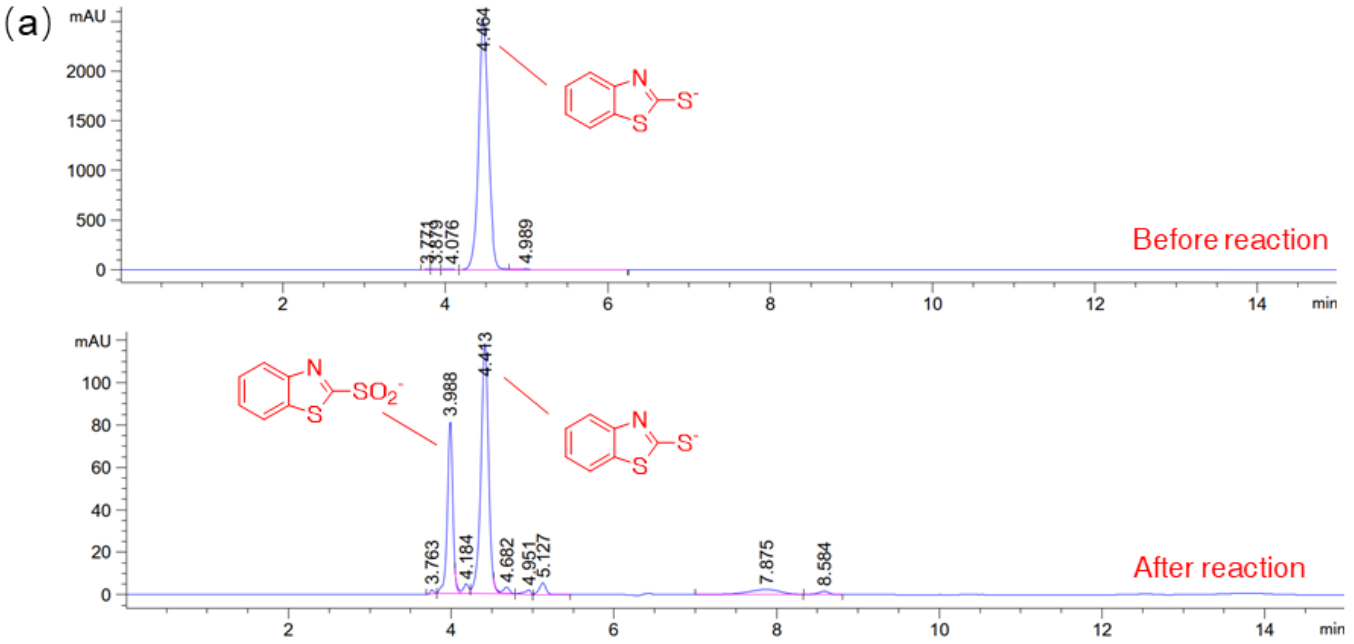

(b)
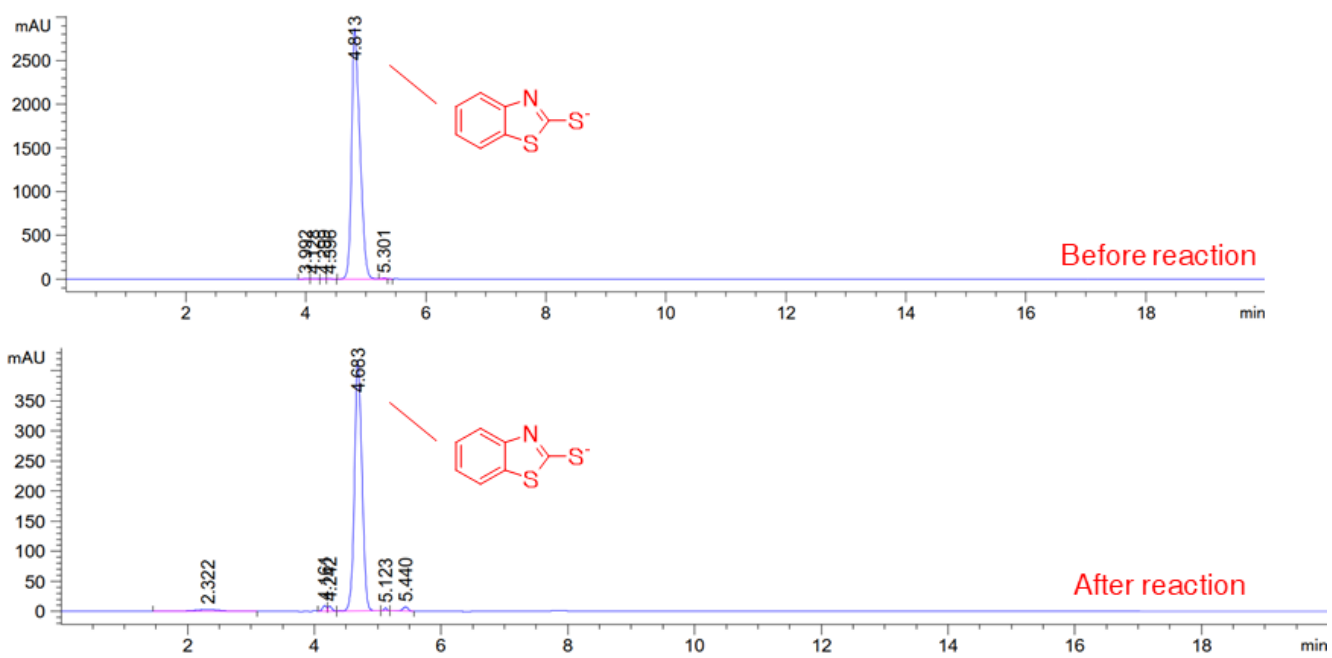

Figure S2. HPLC chromatograms of the reactant before reaction and the mother liquor after separating the solid product under the condition of (a) Entry 11. (b) Entry 10. $\left(0.5 \mathrm{~mL} / \mathrm{min} 70 \% \mathrm{NH}_{3} \mathrm{HCO}_{3} / \mathrm{NH}_{3} \mathrm{H}_{2} \mathrm{O}\right.$ aq $(\mathrm{pH}=10.5)$ and $30 \%$ acetonitrile as the mobile phase) 
Table S1. Values and confidence intervals of $k_{\mathrm{obs}}$

\begin{tabular}{llll}
\hline $\begin{array}{l}\text { Temperature } \\
\left({ }^{\circ} \mathrm{C}\right)\end{array}$ & $\begin{array}{l}c_{\text {PTA }} \\
(\mathrm{mol} / \mathrm{L})\end{array}$ & $\begin{array}{l}\text { Values of } k_{\mathrm{obs}} \\
\left(\mathrm{mol}^{-1} \mathrm{Ls}^{-1}\right)\end{array}$ & $\begin{array}{l}k_{\mathrm{obs}}\left(\mathrm{mol}^{-1} \mathrm{Ls}^{-1}\right) \\
95 \% \text { confidence intervals }\end{array}$ \\
\hline 50 & 0 & 0.0064 & $0.0050 \sim 0.0077$ \\
& 0.00156 & 0.015 & $0.014 \sim 0.016$ \\
& 0.00312 & 0.027 & $0.022 \sim 0.032$ \\
\hline 60 & 0.00625 & 0.050 & $0.046 \sim 0.053$ \\
& 0 & 0.0091 & $0.0082 \sim 0.010$ \\
& 0.00156 & 0.024 & $0.022 \sim 0.026$ \\
& 0.00312 & 0.053 & $0.050 \sim 0.055$ \\
& 0.00625 & 0.084 & $0.077 \sim 0.091$ \\
\hline 70 & 0 & 0.019 & $0.018 \sim 0.020$ \\
& 0.00156 & 0.056 & $0.054 \sim 0.057$ \\
& 0.00312 & 0.075 & $0.064 \sim 0.085$ \\
& 0.00625 & 0.13 & $0.12 \sim 0.14$ \\
\hline
\end{tabular}


Table S2. Values and confidence intervals of $E_{\mathrm{a} 0}$ and $E_{\mathrm{ac}}$

\begin{tabular}{|c|c|c|c|}
\hline Values of $E_{\mathrm{a} 0}$ & $E_{\mathrm{a} 0}\left(\mathrm{kJmol}^{-1}\right)$ & Values of $E_{\mathrm{ac}}$ & $E_{\mathrm{ac}}\left(\mathrm{kJmol}^{-1}\right)$ \\
\hline \multirow[t]{2}{*}{$\left(\mathrm{kJmol}^{-1}\right)$} & $68.27 \%$ confidence & $\left(\mathrm{kJmol}^{-1}\right)$ & confidence \\
\hline & intervals & & intervals \\
\hline 64.77 & $52.32 \sim 77.22$ & 42.67 & $38.15 \sim 47.18$ \\
\hline
\end{tabular}


(a)

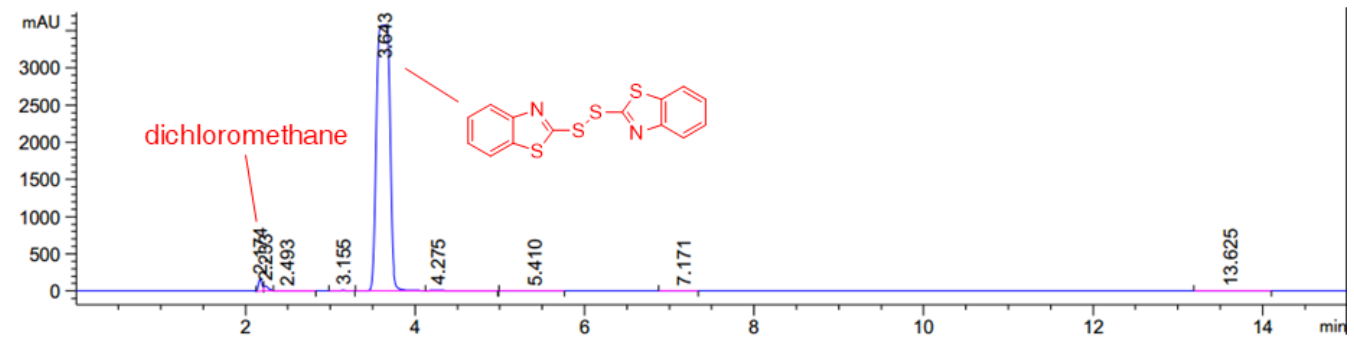

(b)

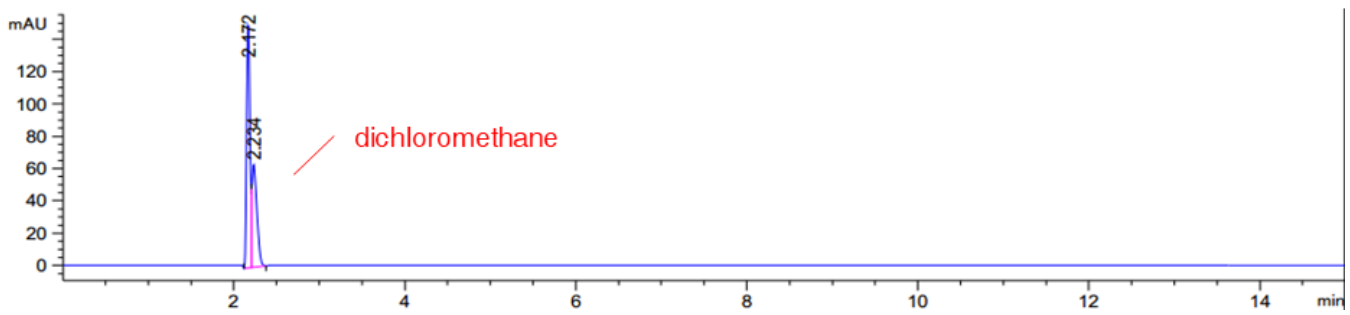

Figure S3. HPLC chromatograms of (a) the solid product dissolved in dichloromethane. (b) dichloromethane. $(0.5 \mathrm{~mL} / \mathrm{min}$ acetonitrile as the mobile phase) 
2,2'-Dibenzothiazole disulfide. $1 \mathrm{H}$ NMR $(\mathrm{CDCl} 3,600 \mathrm{MHz}, \mathrm{ppm}) \delta 7.938$ (d, 1H, $J=$ $8.25 \mathrm{~Hz}), 7.771(\mathrm{~d}, 1 \mathrm{H}, J=7.79 \mathrm{~Hz}), 7.465$ (t, $1 \mathrm{H}, J=7.79 \mathrm{~Hz}), 7.356$ (t, 1H, $J=7.79$ $\mathrm{Hz})$.

(a)

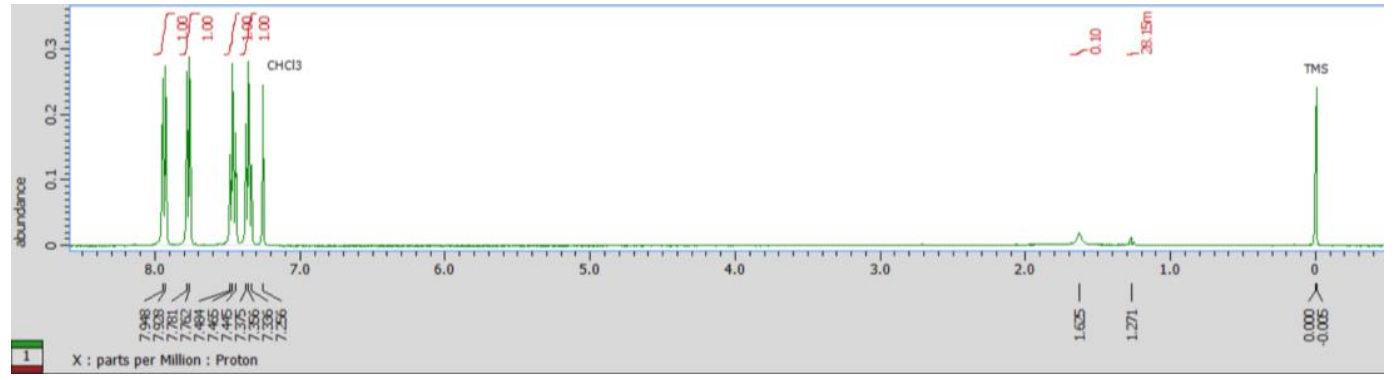

(b)

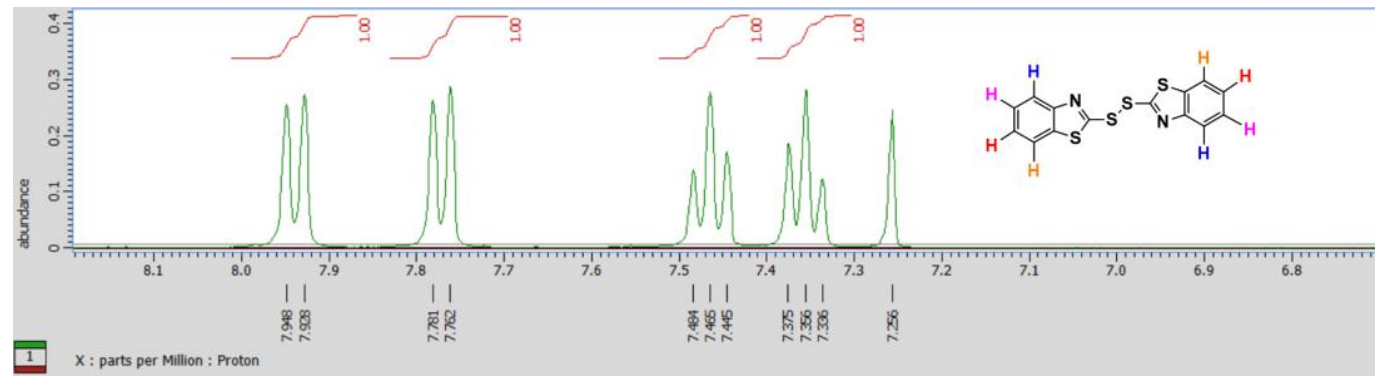

(c)

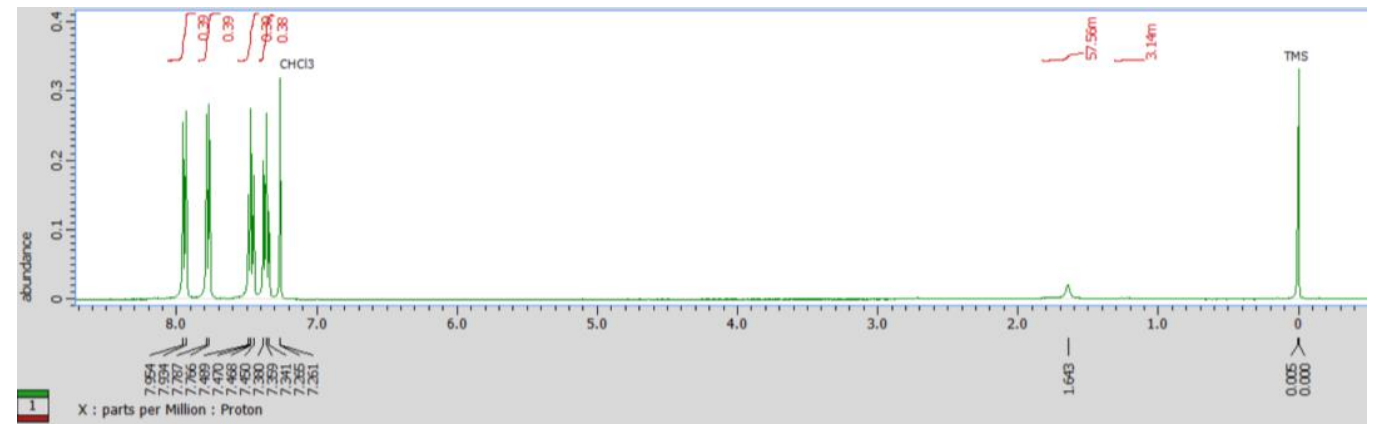

Figure S4. 1H NMR spectra of (a) the obtained product. (b) the obtained product (partially zoomed in). (c) the commercial pharmaceutical grade MBTS.

In Figure S4(a) and Figure S4(b), the chemical shifts at 7.938, 7.771, 7.465, and $7.356 \mathrm{ppm}$ correspond to the four kinds of hydrogen atoms in the MBTS molecular structure, respectively. The ratio of peak area integration is $1: 1: 1: 1$, which is consistent with the ratio of the number of hydrogen atoms in different positions in the molecular structure. And the split numbers of the above four groups of peaks are 2, 2, 3, 3, suggesting that the number of hydrogens on the adjacent carbon atoms are 1, 1, 2, 2, respectively, which is also consistent with the molecular structure of MBTS. There are very faint peaks in the chemical shift between 1.0 and 2.0, which is also found in the 1H NMR spectrum of commercial medical grade MBTS, as shown in Figure S4(c). The results show that the obtained product has a very high purity, which is comparable to pharmaceutical grade products. 